\title{
Ring Irrigation System (RIS) design through customer preference representation
}

\author{
Infandra I.Z. Ridwan, Suchada Rianmora ${ }^{*}$, and Siwat Werawatganon
}

School of Manufacturing Systems and Mechanical Engineering (MSME), Sirindhorn International Institute of Technology, Thammasat University, 12121 Pathumthani, Thailand

\begin{abstract}
In agricultural field, irrigation is one of the most interesting considerations affecting the rate of plant growth and development. Micro-irrigation as the dripping or sprinkle method is one of the irrigation types that applies the small amount of water for fulfilling the humidity requirement. The most important factors affecting the demand of water for plants are soil conditions and effect of climatic factors. With less human labour required, to improve the irrigation method from the recent days, analyzing water used or water permeation automatically through the soil moisture has been raised as the interesting topic. Proposed in this research is the ring irrigation system (RIS) which is introduced as an alternative channel for emitters that drip water directly onto the soil at the plant's root zone where the soil conditions before and after watering can be quickly detected by the sensors. This RIS can be used for the potted plant, green house, or other small farm fields. Product design and development (PDD) is applied in this research for assisting the designer to understand and create the RIS prototype properly according to the customer's requirements where the suggested functions obtained will be added and tested.
\end{abstract}

\section{Introduction}

During the recent decades, manufactures invest the amount of money to upgrade their product to achieve business competitiveness. An improvement sometimes just focuses on technical requirements in the explicit form. To guide the improvement, the comprehensive design takes attention on the customer perception and preference. In addition, technical merit with the marketplace analysis can minimize gaps between practice and theory. Instead, qualitative and subjective factors like usability, appearance, and comfort become imperative [1]. To quickly achieve their targets, the concept of product design development (PDD) has been applied. PDD is the innovation that decides the added value of the existing product to the specific product design [2]. Considering product development as knowledge-based capabilities, these processes help the firm to build its competencies and to learn about new technologies that can be exploited in order to serve market demands [3]. Two stages of PDD are concept development and system level design. In concept development has many activities which involve creating, adding, testing, modifying, and refining physical characteristics of a new product item. This stage has been applied for assisting the engineering design to fulfill the customer needs or support current market trends. In the second stage is system level design. This stage is performed where the designers and engineers develop the product architecture in detail, and manufacturers determine which components should be made or purchased, and identify the necessary suppliers.
Currently, PDD has been applied in various agricultural fields for obtaining high efficiency of farming works. World water assessment program explains that the future agricultural product consumption increases $70 \%$ based on the growth of the global population 2-3 billion people by 2050 and require more than $50 \%$ water consumption than was needed in 2012 [4]. Based on that, there were approximately 847,163 people in Central Region of Thailand decide to be farmers. The characteristics of farm operator households and their farm businesses have been analyzed and considered mainly on water resources [5]. It means that some experiments in the agricultural field which has already built in the laboratory should be implemented in the real farm further. Moreover, the product which gives the automation can provide the customers not only for the farm field but for the customers who have less place for planting also customers who cannot irrigate the plant in scheduling referred to timing and amount to make most efficient water. Especially, the product knowledge explores to the customer for making the easiest way to get information when product launch in the market.

Utilization the water resources as the traditional irrigation still popular to be used by the people in the past until in this era to saturate water in the agricultural field. This irrigation maximizes water resource near the planting field. Farmers build the small canal to flow the water into the field then they divide the water for all nearest farmers. The other way, farmers use diesel pump to flow water into the field. This method is suitable to use if the water resource is abundant and the location of the

\footnotetext{
* Corresponding author: suchada@,siit.tu.ac.th
} 
planting field is near the water resource like weir or river to supply anytime they want. Otherwise, farmers mostly use underground soil water if their field is not included in that condition. The significant change of environment in Thailand drives people to anticipate in every condition. Explained by Wichitarapongsakun [6], water security and drought become critical issues in Thailand and the greatest damage was in 2005 covering 71 provinces. He also explained that the Sakae Krang River, one of the main river basin, could supply only $62.51 \%$ of demand [6].

In order to support the water unpredictable condition, the people have built and used the irrigation system in their planting fields; the most popular one is micro irrigation system. For this system, the gravity flow or conventional pump from the water tank is replaced by dripping or sprinkler irrigation. The sprinkler device is designed for almost every garden size and shape, it is placed on the topmost surface layer of the soil as shown in Fig. 1 [7]. Using this method can save up to $50 \%$ on the water bill.

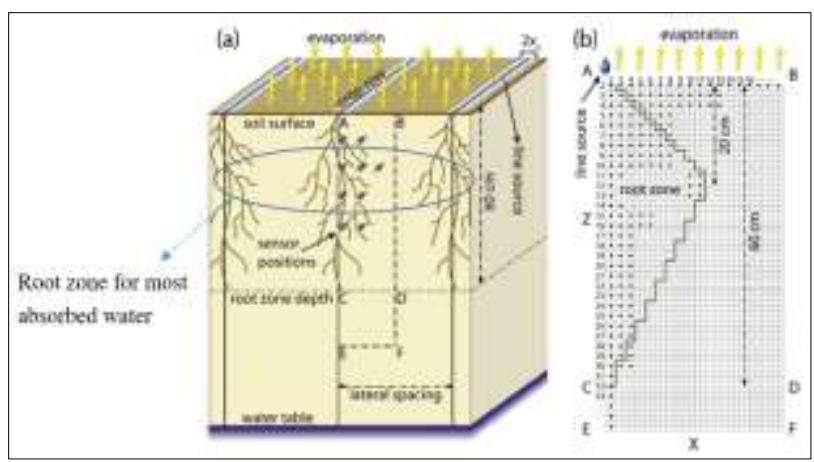

Fig 1. Dimensional physical model of surface micro irrigation system [7].

However, this irrigation faces the problem of providing insufficient amount of water since the irrigated water is uncontrollably; water that accidentally overflows. In active roots, there is a zone with root hairs. This zone is actively absorbing water and mineral nutrients. For the potted plants, small root hair, sometimes, can absorb massive quantities of water which might have the direct effects on overhydration. The ways to provide water of adequate quantity and quality have been studied and researched for supporting various styles of gardening.

\section{Research Background}

\subsection{Customer Knowledge for Product Design}

Customer may have the knowledge for the product development in the market. There is no limitation for the customer to get the new product knowledge which is based on generating and integrating customer information throughout the organization because the processes of generating and integrating customer knowledge are embedded in organizational cognitive activities and are not observed readily from outside. Customer knowledge was conceptualized by the impact of market knowledge on product advantage. To get that knowledge, the customers have information process refers to the set of behavior activities that generate customer knowledge pertaining to customers' current and potential needs for products and services [8]. In the market also exist several products to support every activity. The customers can choose the preferable product that has a different type of product as their own requirement. People also have the basic need for their life. When the people want to buy the product, they will consider many things to satisfy their feeling [9].

\subsection{Development of Irrigation System Design}

Irrigation plays a vital role in increasing plant yields and stabilizing production. Irrigation may be defined as the application of water to soil for the purpose of supplying the moisture essential for plant growth. In dry and semidry regions, irrigation is essential for economically feasible agriculture, whereas in semi-humid and humid areas, it is often required on a supplementary basis. Some of the most important factors affecting the demand of water for field-grown plants are: nature of plants; nature of soil; effect of climatic factors; effect of nature of irrigation; and attack of pests and diseases [10 - 12].

The method for water management consists of periodic flooding or sprinkling and dryness prediction during the soil water scarcity [13]. Advance technology in the agricultural generates the development of irrigation system. Several solutions have been proposed the requirements for plant growth. Temperature is a primary factor affecting the rate of plant development [14 - 15]. Farmers mostly used the semi-automatic equipment to watering their plant. In practices, they know the automatic irrigation is the device that used the timer to control the valve open and close and the setting time. In other case, irrigation has already supported with sensor shield for applying the smart farming. Sensors help to collect the information about the environmental attributes, give the feedback and accumulate information to have the control situation [16]. Sensors explained by Abbasi [16], are most widely used for indicating the conditions of soil where temperature, moisture, water flow, and salinity can be measured. To make more efficient used of water, the sensors are applying with the micro irrigation system like the sprinkler or dripping irrigation.

The basic of micro irrigation is used principles of hydraulic of pressuring flow from a pipe. Micro irrigation not only minimizes the problem in traditional irrigation but also provides higher water productivity [17]. However, this method well-known with the effectiveness, it still depends on the users how to create and make the combination of all devices correctly with the environment. The micro irrigation is determined by water requirement for given irrigation interval on the planted area. The affected of micro irrigation is from basic variation, hydraulic design, emitter grouping, emitter spacing and plugging [18]. The researchers tried to reveal the customer requirement for the purposed design of automatic irrigation with used the ring emitter. This device is called ring irrigation system (RIS). 


\subsection{Customer Perceived Utility of the Design}

Before starting to design ring irrigation system (RIS), the researchers have tried to reveal the basic requirements and hidden needs from 150 respondents who were interviewed and discussed about their opinions (via self-administered questionnaires). The questions will be focused about the urban people who need to grow the plant, the problems occurred, and the ways to solve the problems.

Question 1: How to grow the plant?

Question 2: How do you manage to irrigate your plant, garden or farming land?

Question 3: What is your irrigation problem during the cultivation?

Table 1. How to grow the plant

\begin{tabular}{|c|c|}
\hline How & \% of respondents \\
\hline Home farming or garden & 41.18 \\
\hline Potted plant & 27.45 \\
\hline Farm field & 25.49 \\
\hline Vertical planting & 3.92 \\
\hline Greenhouse & 1.96 \\
\hline
\end{tabular}

Table 1 presented the results of Question 1 which was about "the way to grow the plant". The highest percentage was shown though "growing plant in home farming or garden" because they thought that the space required for this planting was quite small and might be easy to manage, whereas the greenhouse style was required larger space and the proper infrastructure was the main issue for well planting.

Table 2. The way to manage the irrigate your plant

\begin{tabular}{|c|c|}
\hline How & \% of respondents \\
\hline Manual irrigation & $37 \%$ \\
\hline Automated irrigation system & $27 \%$ \\
\hline Used water pump system & $25 \%$ \\
\hline $\begin{array}{c}\text { Used the water flow from the river } \\
\text { of out source }\end{array}$ & $11 \%$ \\
\hline
\end{tabular}

Table 3. Problems

\begin{tabular}{|c|c|}
\hline Problem & \% of respondents \\
\hline Not scheduled time of irrigation & $44 \%$ \\
\hline Limited water & $31 \%$ \\
\hline Watering in unnecessary area & $16 \%$ \\
\hline Over flow of water & $5 \%$ \\
\hline Others & $4 \%$ \\
\hline
\end{tabular}

The results of Question 2 and 3 were shown in Table 2 and 3. All interviewed data and analysis were interpreted into the rough design where the main function of the developed machine will be created according the potential direction of how to manage the irrigation of flowers or plants in the urban areas. $37 \%$ of the respondents decided to apply "the manual irrigation" where the valve was closed and opened manually by human. The soaker hoses, sprinkler hoses (water mist systems) and water conservation for the home were mentioned and discussed.

Watering of the plants like this manual method was suffering where the inadequate amounts of water might cause the plant death by overhydration (i.e., excessive water intake). In general, the comments were shown about watering plants in the cool of the evening or the very early morning; less water is lost.

The irrigation problems were discussed and grouped. The majority problem was shown through "Not scheduled time of irrigation" answer which was approximately $44 \%$. This interviewed data could be considered as the issue for selecting the "the automated irrigation system" (27\% of the respondents) where the automatic battery-operated garden irrigation system with home watering timer device, and electromagnetic valve timer controller were applied. This system could operate to open the valve in seconds, minutes or hours, and the irrigation frequency (e.g., 2 times/day or 1 time/30 days) could be set.

$25 \%$ of the respondents chose "the water pump system" for increasing the pressure of the water for a long distance during watering the plant. The water from natural resource as river, groundwater or pond was still in consideration for $11 \%$ of the respondents for saving cost.

However, using the timer to close or open the valve automatically cannot minimize the risk of overhydration since the soil's conditions are not taken into considerations. Optimizing water for home farming or gardening properly by detecting the specific soil's conditions should be focused.

\section{Conceptual and System Level Design}

\subsection{Conceptual Design}

In current years, automatic irrigation devices have widespread in the market. The way to irrigate this device is using timer. The automatic irrigation will flow the water at the specified time which is already set by the user. Providing timer irrigation can save time during watering plants and less handling from the user. However, it always flows the water at the time setting even the soil humidity is still high or while raining.

Commonly, micro irrigation devices apply the sprinkle to water the plant in the large field with a large amount of water. Sometimes the water drops in the unnecessary areas which cannot be absorbed by the root of the plant. Overflow of water can make inefficiency of water used and makes oversaturated for the plant root.

The proposed ring irrigation system (RIS) will be developed by using the integration concepts among micro irrigation, submerged irrigation and watering potted plant where the water is emitted as the ring-like spraying subsurface direction, and the soil condition can be identified by the sensors for properly preparing the cultivation. Water is permeated from the circle-shape emitter with the small discharge; only a small amount of water sprayed. The emitter is embedded in the soil subsurface around the plant root.

In conclusion, "the circle-shape water emitter" is the main component of the system to distribute water from 
storage tank to the planted area according to the soil conditions. This system can be applied to various agricultural fields, especially in the drought condition or the place that has limited water resources. For these systems can be applied in the small holder agricultural areas. This innovation is derived for addressing in the potted plant to substantiate the sustenance of agricultural practiced by a small and marginal farmer. The concept of watering design is presented in Fig. 2.

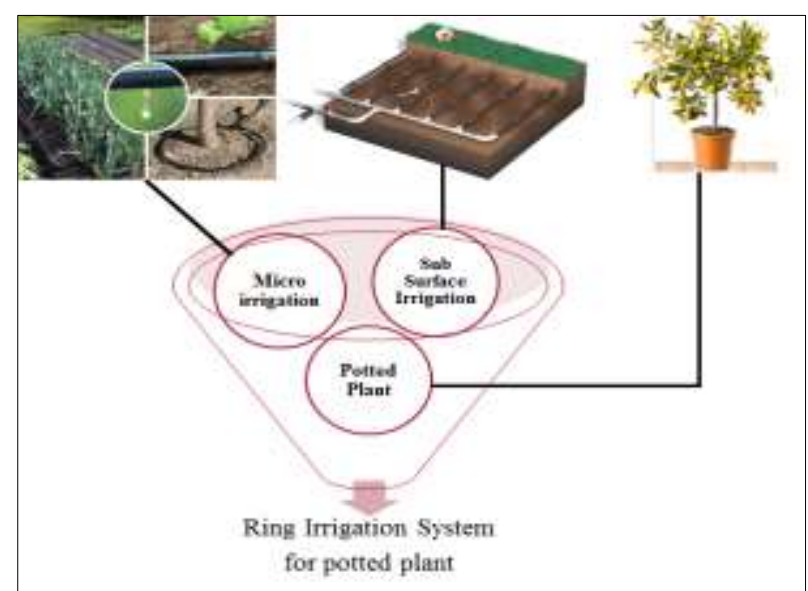

Fig 2. The concept of watering design

Machine embodies the following themes:

Design: It is designed to combine to support for the people who want to grow the plant with some obligation. Not just automatic flowing water like timer irrigation, the automation of ring irrigation system (RIS) combined with the ring emitter can support the people who would like to grow the plant with less handling and using optimum water during the cultivation. For supporting the one who has less time to water and take care of the plant, using the proposed RIS can flow the water with a suitable amount automatically by itself based on the soil condition.

Function: Providing the 3 sensors as temperature, moisture and light sensors can indicate and check the soil condition to flow the water properly to the plant. These sensors and components are controlled by microcontroller for supporting the automation work. Ring emitter placed in the subsurface of the plant will disperse a small amount of water directly to the root. This ring emitter also transfers the nutrient during the irrigation.

Protection: When either one of these three sensors are broken; the soil conditions cannot be detected properly and even less misleading measures may have the direct effects to the plant for surviving. Therefore, the controller will switch itself to apply the "time constraint" mode immediately for releasing the water in pattern.

Based on the climate condition and water resource in Thailand, the researchers have tried to study and analyze the condition of the soil for creating some constraints and boundary for the amount of water used. Since the ring emitter is to be submerged under the soil for a long time; the material property of the ring should be well considered. The drafted idea of the proposed RIS is presented in Fig. 3.

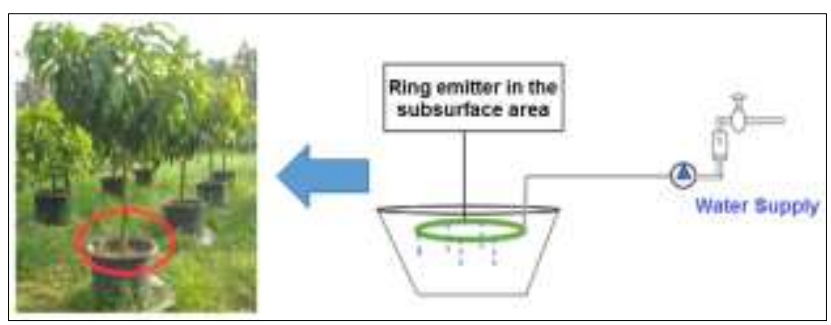

Fig 3. Drafted design of the proposed ring irrigation system (RIS)

\subsection{System Level Design of Ring Irrigation}

Soil water balance is the main factor for irrigation scheduling. In this RIS, the 3 sensors are added to form the automatic system to control the valve and pump for stopping or releasing the water from the source. The ring emitter applied in this RIS is made from the elastic material and can maintain its shape during varied conditions; steady shape like rubber hoses, shown in Fig. 4 and Table 4 show the description of the component. The size of hose is $5 / 8$ inch (internal diameter $16 \mathrm{~mm}$ ) and making the circle with $15-\mathrm{cm}$ diameter.

\section{Discussion}

\subsection{Device Performance}

Fig. 5 shows the soil moisture reading for the condition of humidity in the soil. This result shown the device work to read of soil condition. The sensor is put into the center of root area and analyze the water content in the soil during the cultivation. The sensor detects the humidity and saved in the SD card module that is connected with microcontroller. It is clearly repeated in 24 hours in the suns time and in the cools time at the night. The plant analyzed with this RIS was "pak-choi" (collards leaves vegetables) that was analyzed in the small green house to control the water content from the rain. But the researchers cannot control the moisture from the dew in the morning.

The irrigation activity would be started when the sensors detected the condition as dryness, immediately, the water was released from the tank to the root area via the ring emitter. The observations had been performed during 19-28 August 2017, this month is still in the rainy season and it rains almost everyday where the dew always shows in the morning and the evaporation rate reduces [19]. 


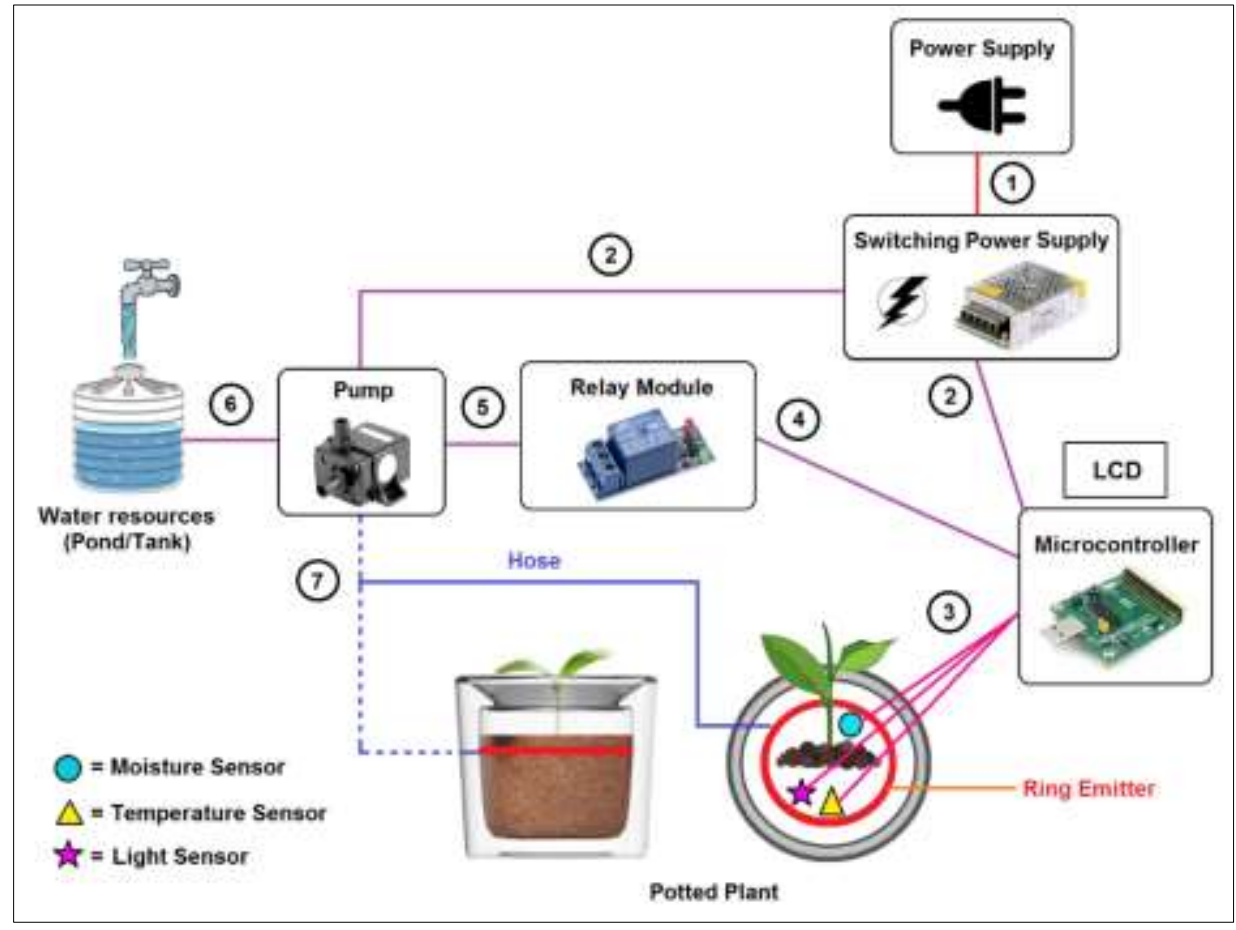

Fig 4. Schematic diagram of the ring irrigation

Table 4. Description path of the ring irrigation diagram

\begin{tabular}{|c|c|c|}
\hline Path & Related equipment & Descriptions \\
\hline & Power supply & $\begin{array}{l}\text { The electrical energy is transferred to switching power supply. This } \\
\text { power supply is the only main power for the RIS device }\end{array}$ \\
\hline & Switching power supply & $\begin{array}{l}\text { This component has output DC } 5 \text { Volts; } 35 \text { Watts; } 7 \text { Amperes to control } \\
\text { the conversion of electrical power. }\end{array}$ \\
\hline & Sensors & $\begin{array}{lll}- & \text { Moisture sensor: } & \text { soil moisture sensor module (LM393) } \\
\text { - Temperature Sensor: } & \text { NTC thermistor temperature module } \\
\text { - Light Sensor: } & \text { LDR photo resistor module } \\
\end{array}$ \\
\hline & Relay module & This component uses 2 channels with 5 Volts and 10 Amperes \\
\hline & Pump & $\begin{array}{l}\text { The maximum flow is } 240 l / h r \text { with } 4.8 \text { Watts and it can support feeding } \\
\text { water downwardly or upwardly through the tube with } 3 \text { m-apart from the } \\
\text { ground level. }\end{array}$ \\
\hline & Water resources & $\begin{array}{l}\text { RIS device does not require the process to place water tank on an } \\
\text { elevated height. Pond is also accepted. }\end{array}$ \\
\hline & Hose & $\begin{array}{l}5 \mathrm{~mm} \text {-diameter hose is required to flow water from the water resources } \\
\text { to the ring emitter. }\end{array}$ \\
\hline
\end{tabular}

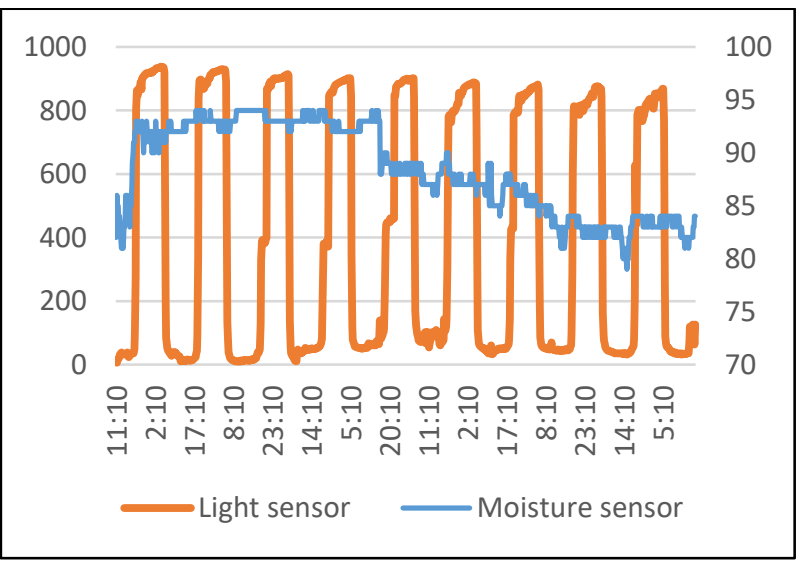

Fig 5. Water content in the soil using moisture sensor
The potted plant was selected because this was the most convenient gardening methods for analyzing data. From the graph, the value detected by the moisture sensor kept decreasing slightly in the middle, it caused the device to indicate the dryness of the soil and read the water content in the soil. Comparing the data obtained between two sensors; moisture, and light sensors, they provided the additional knowledge that, under the high-intensity sunlight, the light sensor presented the low level and decreasing in the level of soil humidity. The highest level of the soil humidity was at the beginning after the device released the water into the soil ( $95 \%$ of the soil humidity). The lowest level was $79 \%$ of soil humidity. 


\subsection{Customer Preference on the Proposed Design Utility}

The researchers have tried to figure out the ways for revealing the hidden requirements; two sets of selfadministered questionnaires were raised at the concept development stage, and the detailed design stage, respectively. After accomplishing the conceptual design of the ring irrigation system (RIS), 150 respondents experienced in planting were asked and represented as the customers. Six issues presented in Fig. 6 were asked as the key considerations for the second set of questionnaires. A question was answered with a simple "Yes" or "No". Saying "Yes" on which particular function implied a chance that the designed utility might be survived in the real application was in the high level. 102 respondents who answered "YES" were analyzed about their opinions, ideas and acceptances on the designed functions.

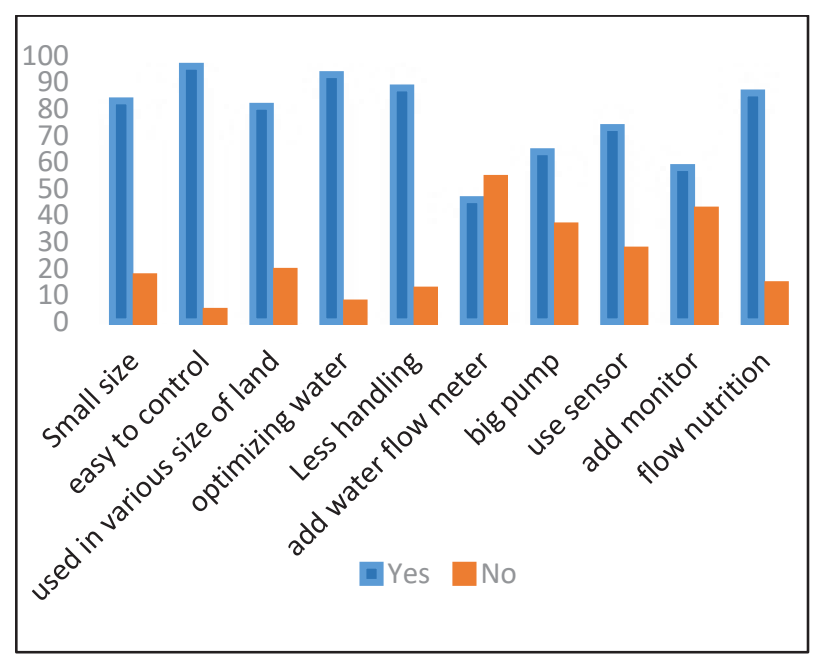

Fig 6. Percentage of customer preference on the proposed engineering issues

The first issue was focused on "the size of the device". $83 \%$ of the customers who answered "YES" preferred the smaller size since they could place it everywhere even in limited area. The second issue is about "easy to control and use" and $96 \%$ of customers needed to apply the userfriendly interface and applications. The control buttons and switches should be put at obvious and reachable positions, and $58 \%$ of customers required LCD screen for monitoring the real-time condition data of soil moisture, temperature and light measurement from sensors. For the connected components, either identical or disjoint, they should let the users get plugged in easily; this can make the device more convenient.

The third issue was about "garden space and size", the customers wondered what the area of garden is to apply one unit of the developed device. $81 \%$ of customers expected to have the multifunction device that could be applied in various sizes of land; the size of the pump was taken into consideration for supporting this requirement; $64 \%$ of the customers required a big pump for supporting a large scale of the planting field.
The forth issue was mentioned about "optimizing water used" and $93 \%$ of customers required the extra function for measuring the amount of water used. In this era, they have already had the knowledge about the efficiency of using water resource. The effect of some environmental conditions or factors (e.g., during the drought season) is significant; a plant stress usually reflects some sudden change in environmental condition. The irrigable areas through supplemental irrigation for different plants are provided to ensure optimal plant growth.

The fifth issue was about "less handling and less human labour required" where $88 \%$ of customers needed the automation system where the developed device should function by itself after being adjusted and assigned the watering parameters by the user. It would save time and reduce the number of watering activities rather than using the irrigation manually. The flow meter $(46 \%$ of customers) and sensors (73\% of customers) were mentioned and required for the new design. Moreover, applying sensors could help the users to easily recognize and indicate the real-time condition of the soil and planting environment comparing to the timer-valve application. Once people start to become aware of how much water they use, they would be able to start saving water by considering the water flow meter since it would measure the flow rate or quantity of water. The last issue was about "flowing nutrients". $86 \%$ of customers required the specific function of the watering device that could transfer the nutrients with water directly to the root zone.

However, 48 respondents who answered "NO" (they disagreed with researchers) even before knowing the whole explanation of the provided functions. $90 \%$ of those respondents explained briefly about their reasons, the interesting opinion was that the advance functions and devices would have direct effects on the price ( $49 \%$ of the respondents). Whereas another $10 \%$ had no comments or ideas of the watering design; all components might be necessary and required as shown in Fig. 7.

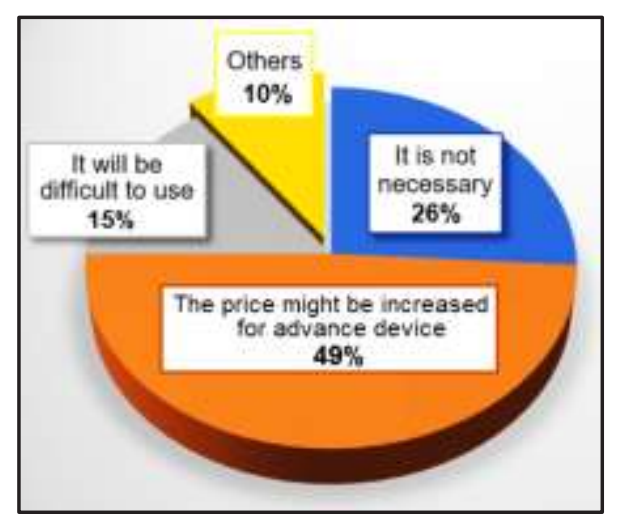

Fig 7. Other opinions of the customers on the developed design

The comments from Fig.7 can be applied for modifying the new version of irrigation system where the material selection and automatic functions will be the priority consideration to minimize the cost while maintaining high accuracy and reliability of the system. 
For the contribution of the proposed system, the manufacturer or designer can define and identify the suitable device or equipment to support the customers who live and grow the plants in the small space/area by using "ring irrigation system-RIS". The new generation of automatic filling water can be modified and adapted for supporting the customer's requirements where the chance for producing waste materials or lack of design pattern can be eliminated before starting the conceptual design phase.

In term of marketing point of view, the designer or manufacturer should make and provide a prototype or effective final demo presentation about product's descriptions to the customers directly and clearly for increasing the selling/buying volumes. The clean and clear advertisement can be recorded as the good perception for purchasing decision.

\section{Conclusions}

Ring irrigation system (RIS) is the development of micro irrigation to support an automated watering system where the amount of water applied onto the area of interest can be optimized based on the environmental conditions. The specification of RIS has been considered and created according to the customer preference representation. Customer preference refers to their expectations and behaviors on a product where its function can be revealed and extracted into the specific characteristics by the concept of product design and development (PDD). Applying the proposed technique can support the manufacturer or designer to achieve the optimal design of the automated watering system where the number of trialand-error activities can be minimized.

Three main issues about the function of RIS identified from the target customers' preferences (these might have the direct effect on purchasing decisions) are; less handling and labour required, water optimization, and easy to operate the device.

Moreover, as expected, most of the interviewed women and men reside in rural areas, price is the most consideration for buying decision. Therefore, to build the second prototype without ignoring the main function, the extra devices "water flow meter" and "real-time monitor or digital screen" are not recommended to apply.

For the future work, the obtained prototype will be tested refined more in various soil/weather/moisture conditions for supporting different types of environment and the potted plants can be grown up easily and quickly. This contribution can be applied in the large fields or farms where the design of the effective ring irrigation might be changed and modified while minimizing operational cost.

\section{References}

1. Y. Wang, and M.M. Tseng, Integrating comprehensive customer requirements into product design. CIRP Annals-Manufacturing Technology, 60(1), 175-178. (2011)
2. L. P. Khoo, C. Chen, W. Yan An investigating on a prototype customer oriented information system for product concept development. Computers in Industry. 49, 157-174. (2002)

3. O. C. Racela, Customer Orientation, Innovation Competencies, and Firm Performance: A Proposed Conceptual Model. Procedia-Social and Behavioral Sciences, 148, 16-23. (2014)

4. WWAP (World Water Assesment Programme). Managing Water Under Uncertainity and RiskUnited Nations World Water Assessment Programme United Nations World Water Development Report 4. The United Nations Educational, Scientific and Cultural Organization, Paris, France. Available: https://goo.gl/gm6igd (2012)

5. National Statistic of Thailand. Number of holdings by agricultural registration of holder and size of total area of holding in 2013. Accessed on 23 August 2017 [online]. Available: https://goo.gl/786kvv (2013)

6. P. Wichitarapongsakun, C. Sarin, P. Klomjek, and S. Chuenchooklin, Rainfall prediction and meteorological drought analysis in the Sakae Krang river basin of Thailand. Agriculture and Natural Resources, 50(6), 490-498. (2016)

7. K. X. Soulis, S. Elmaloglou, and N. Dercas, Investigating the effects of soil moisture sensors positioning and accuracy on soil moisture based drip irrigation scheduling systems. Agricultural Water Management, 148, 258-268. (2015)

8. A. J. Campbell, Creating customer knowledge competence: managing customer relationship management programs strategically. Industrial Marketing Management, 32(5), 375-383. (2003)

9. B. Poston, An Exercise in Personal Exploration: Maslow's Hierarchy of Needs. Association of Surgical Technologists. (2009)

10. Natural Resources Management and Environment Department (NRMED), Water treatment and use in agricultural. Food and Agriculture Organization corporate document repository. Accessed on 26 August 2017 [online]. Available : https://goo.gl/qG9V4n (1992)

11. Department of Primary Industries, Chapter D9: Irrigation scheduling. NSW Government. Accessed on 28 August 2017 [online]. Available: https://goo.gl/qgSxig. (2007)

12. Raghav, 5 Important factors affecting the demand of water for crops. Accessed on 23 August 2017 [online]. Available: https://goo.gl/gXwDRj. (2017)

13. F. Olszewski, P. Jeranyama, C.D. Kennedy, and C.J. Demoranville, Automated cycled sprinkler irrigation for spring frost protection of cranberries. Agricultural Water Management, 189, 19-26. (2017)

14. T. Foster, N. Brozovic, and A.P. Butler, Why well yield matters for managing agricultural drought risk. Weather and Climate Extremes. 10, 11-19. (2015) 
15. L.H. Jerry, and H.P. John, Temperature extremes: Effect on plant growth and development. Weather and Climate Extremes. 10, 4-10. (2015)

16. A. Z. Abbasi, N. Islam, and Z. A. Shaikh, A review of wireless sensors and networks' applications in agriculture. Computer Standards and Interfaces, 36(2), 263-270. (2014)

17. M. Kumar, N. Kumar, K.P. Singh, P. Kumar, K. Srinivas, and A.K. Srivastva, Integrating water harvesting and gravity-fed micro-irrigation system for efficient water management in terraced land for growing vegetables. Biosystems Engineering, 102(1), 106-113. (2009)
18. J. Barragan, L. Cots, J. Monserrat, R. Lopez, and I. P. $\mathrm{Wu}$, Water distribution uniformity and scheduling in micro-irrigation systems for water saving and environmental protection. Biosystems Engineering, 107(3), 202-211. (2010)

19. Thai Meteorological Department. Weather forecasting in central Thailand. Accessed on 30 August 2017. Available: https://goo.gl/sSNarB. (2017) 